\title{
Robust PID Controller for a Pneumatic Actuator
}

\author{
Michael G. Skarpetis ${ }^{1, a}$, Fotis N. Koumboulis ${ }^{1}$, George Panagiotakis ${ }^{1}$ and Nikolaos D. Kouvakas ${ }^{1}$ \\ ${ }^{1}$ Department of Automation Eng., Technological Educational Institute of Sterea Ellada, 34400 Psahna Evias, Chalkida, Greece
}

\begin{abstract}
In this paper the position control pneumatic actuator using a robust PID controller is presented. The parameters of the PID controller are computed using a Hurwitz invariability technique enriched with a Simulated Annealing Algorithm. The nonlinear model involves uncertain parameters due to linearization of the servo valve, variations of the initial volume of the cylinder and variation of the external load. The problem is proven to be solvable and the controller parameters are chosen to provide a suboptimal solution for tracking error minimization. Simulation results are presented for the nonlinear model.
\end{abstract}

\section{Introduction}

The major aspects for controlling pneumatic actuators are the uncertainties appearing in the linear and nonlinear model and the nature of fluid power. Many control techniques such as H-infinity, quantitative feedback theory (QFT) Robust control techniques appear to be effective for controlling the position and the velocity of industrial pneumatic actuators (see f.e. [1]-[12]). These techniques can work properly to linear and nonlinear models and produce accurate system performance despite plant uncertainty as well as plant variations and disturbances.

In this paper a robust PID controller is proposed in order to produce accurate system performance despite plant uncertainty and plant variations and disturbances. The problem is solved using a Hurwitz invariability technique [13], [14] and a Simulated Annealing Technique [11]. First, the nonlinear model of the pneumatic actuator is linearized around equilibrium point. To the linear uncertain system a robust dynamic tracking controller is designed, combining the results in [9], [13] and [14]. The effectiveness of the PID controller is illustrated through simulations for the nonlinear model of the plant and for various values of the model uncertain parameters.

\section{Pneumatic servo actuator model}

The motion of a hydraulic cylinder controlled by a servo valve linearized around an initial spool valve position (see Figure 1) can be expressed by the following set of nonlinear differential equations [3], [4]:

$\dot{P}_{a}(t)=\frac{a R T K_{v} P_{s}}{2\left(A_{p} y_{p}(t)+V_{0}\right)} u(t)-\frac{a P_{a}(t) A_{p}}{\left(A_{p} y_{p}(t)+V_{0}\right)} \dot{y}_{p}(t)$

$$
\begin{gathered}
\dot{P}_{b}(t)=\frac{-a R T K_{v} P_{s}}{2\left(V_{0}-A_{p} y_{p}(t)\right)} u(t)+\frac{a P_{b}(t) A_{p}}{\left(V_{0}-A_{p} y_{p}(t)\right)} \dot{y}_{p}(t)(2) \\
\ddot{y}_{p}(t)=\frac{A_{p}}{M} P_{a}(t)-\frac{A_{p}}{M} P_{b}(t)-\frac{1}{M} F_{L}(t)-\frac{1}{M} \dot{y}_{p}(t)
\end{gathered}
$$

where $P_{a}(t)$ and $P_{b}(t)$ are the pressures in chamber $a$ and $b$ of the pneumatic cylinder, $y_{p}(t)$ is the position of the piston, $u(t)$ is the electro valve input signal, $F_{L}(t)$ is the disturbance force, $M$ is the load mass, $A_{p}$ is the piston area, $V_{0}$ is the air volume when the piston is in the mid position, $R$ is the gas constant, $a$ is the specific heat ratio, $T$ is the temperature of the air source, $K_{v}$ is the valve coefficient and $P_{s}$ is the supplied pressure.

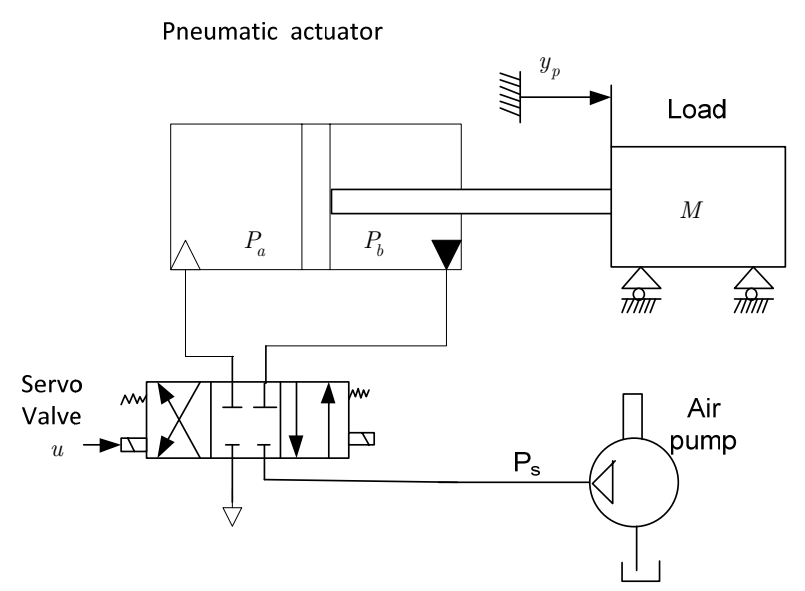

Figure 1. Pneumatic actuator

The nonlinear system in (1)-(3) can equivalently be rewritten as

\footnotetext{
a Corresponding author: mskarpetis@teiste.gr
} 


$$
\dot{x}(t)=f(x(t))+g(x(t)) u(t)+\frac{1}{M} F_{L}(t)
$$

where $x(t)=\left[\begin{array}{llll}P_{a}(t) & P_{b}(t) & \dot{y}_{p}(t) & y_{p}(t)\end{array}\right]^{T}$,

$$
\begin{gathered}
f(x(t))=\left[\begin{array}{l}
-\frac{a P_{a}(t) A_{p}}{\left(A_{p} y_{p}(t)+V_{0}\right)} \dot{y}_{p}(t) \\
\frac{a P_{b}(t) A_{p}}{\left(-A_{p} y_{p}(t)+V_{0}\right)} \dot{y}_{p}(t) \\
\frac{A_{p}}{M} P_{a}(t)-\frac{A_{p}}{M} P_{b}(t)-\frac{1}{M} \dot{y}_{p}(t)
\end{array}\right] \\
g(x(t))=\left[\begin{array}{l}
\frac{a R T K_{v} P_{s}}{2\left(A_{p} y_{p}(t)+V_{0}\right)} \\
\frac{-a R T K_{v} P_{s}}{2\left(-A_{p} y_{p}(t)+V_{0}\right)} \\
0
\end{array}\right]
\end{gathered}
$$

The nonlinear system (4) is linearized around the equilibrium point $\left(P_{a, 0}, P_{b, 0}, \dot{y}_{p, 0}, y_{p, 0}, u_{0}\right)$ yielding the following state space linear uncertain model:

$$
\begin{aligned}
& \Delta \dot{x}(t)=A(q) \Delta x(t)+B(q) \Delta u(t)+D F_{L}(t) \\
& \Delta y_{h}(t)=C \Delta x(t)
\end{aligned}
$$

where

$$
\Delta x(t)=\left[\begin{array}{c}
\Delta P_{a}(t) \\
\Delta P_{b}(t) \\
\Delta \dot{y}_{p}(t) \\
\Delta y_{p}(t)
\end{array}\right]
$$

is the state vector of the linear system, and where $\Delta P_{a}(t)=P_{a}(t)-P_{a, 0}, \quad \Delta P_{b}(t)=P_{b}(t)-P_{b, 0}$, $\Delta \dot{y}_{p}(t)=\dot{y}_{p}(t)-\dot{y}_{p, 0}, \quad \Delta y_{p}(t)=y_{p}(t)-y_{p, 0} \quad$ and $\Delta u(t)=u(t)-u_{0}$ denote small perturbations of the state variables and the input variable around the equilibrium point $\left(P_{a, 0}, P_{b, 0}, \dot{y}_{p, 0}, y_{p, 0}, u_{0}\right)$.

The system matrices are

$$
A(q)=\left[\begin{array}{cc}
-\frac{a \dot{y}_{p, 0} A_{p}}{q_{1}+A_{p} y_{p, 0}} & 0 \\
0 & \frac{a \dot{y}_{p, 0} A_{p}}{q_{1}-A_{p} y_{p, 0}} \\
\frac{A_{p}}{M} & -\frac{A_{p}}{M} \\
0 & 0
\end{array}\right.
$$

$$
\begin{gathered}
-\frac{a A_{p} P_{a, 0}}{q_{1}+A_{p} y_{p, 0}} \quad \frac{a A_{p}\left(2 \dot{y}_{p, 0} A_{p} P_{a 0}-R u_{0} q_{4} P_{s} T_{b}\right)}{2\left(V_{0}+A_{p} y_{p, 0}\right)^{2}} \\
\frac{a A_{p} P_{b, 0}}{q_{1}-A_{p} y_{p, 0}} \quad \frac{a A_{p}\left(2 \dot{y}_{p, 0} A_{p} P_{b, 0}-R q_{4} u_{0} P_{s} T_{b}\right)}{2\left(V_{0}-A_{p} y_{p, 0}\right)^{2}} \\
-\frac{q_{2}}{q_{3}} \\
1 \\
B(q)=\left[\begin{array}{c}
\frac{a R q_{4} P_{s} T_{b}}{2\left(q_{1}+A_{p} y_{p, 0}\right)} \\
\frac{a R q_{4} P_{s} T_{b}}{2 A_{p} y_{p, 0}-2 q_{1}} \\
0 \\
0
\end{array}\right], D=\left[\begin{array}{c}
0 \\
0 \\
\frac{-1}{M} \\
0
\end{array}\right], \\
C=\left[\begin{array}{lll}
0 & 0 & 0 \\
C
\end{array}\right]
\end{gathered}
$$

The vector

$$
q=\left[\begin{array}{llll}
q_{1} & q_{2} & q_{3} & q_{4}
\end{array}\right]=\left[\begin{array}{llll}
V_{0} & f & M & K_{v}
\end{array}\right] \in \mathbb{Q}
$$

is the uncertainty vector involving variations of the initial air volume, variations of the viscous damping coefficient, mass variations and valve gain variations. $\mathbb{Q}$ denotes the domain of uncertainty. The nominal values of the parameters of the system are shown in Table 1 and the expected range of variations of the uncertain parameters is shown in Table 2.

Table 1. Nominal Values for the System Parameters

\begin{tabular}{|l|l|l|}
\hline Symbol & Definition & Nominal Values \\
\hline$A_{p}$ & Piston Area & $0,005 \mathrm{~m}^{2}$ \\
\hline$R$ & Ideal gas constant & $287\left(\mathrm{~J} / \mathrm{Kg}{ }^{*} \mathrm{~K}\right)$ \\
\hline$P_{s}$ & Supply pressure & $4^{*} 10^{5} \mathrm{~Pa}$ \\
\hline$T_{b}$ & Air temperature & $293,15 \mathrm{~K}^{\circ}$ \\
\hline$a$ & Specific heat ratio & 1.4 \\
\hline
\end{tabular}

Table 2. Expected Range of Variations of the Uncertain Parameters

\begin{tabular}{|l|l|l|l|l|}
\hline Symbol & Definition & $\begin{array}{l}\text { Min. } \\
\text { Values }\end{array}$ & $\begin{array}{l}\text { Nom. } \\
\text { Values }\end{array}$ & $\begin{array}{l}\text { Max. } \\
\text { Values }\end{array}$ \\
\hline$V_{0}$ & $\begin{array}{l}\text { Initial air } \\
\text { volume } \\
\left(\mathrm{m}^{3}\right)\end{array}$ & $1.5^{*} 10^{-4}$ & $2.5^{*} 10^{-4}$ & $4^{*} 10^{-4}$ \\
\hline$f$ & $\begin{array}{l}\text { Viscous } \\
\text { damping } \\
\text { coeff. } \\
\left(\frac{N \text { sec }}{m}\right)\end{array}$ & 50 & 60 & 80 \\
\hline$M$ & $\begin{array}{l}\text { Load Mass } \\
(\mathrm{Kg})\end{array}$ & 0.1 & 1 & 2 \\
\hline
\end{tabular}




\begin{tabular}{|l|l|l|l|l|}
\hline$K_{v}$ & $\begin{array}{l}\text { Valve } \\
\text { gain } \\
\left(\frac{K g}{\sec ^{*} V}\right)\end{array}$ & $3.2 * 10^{-3}$ & $3.4 * 10^{-3}$ & \\
\hline
\end{tabular}

\section{Robust PID controller}

To the open loop system (5) apply the PID controller (see Figure 2):

$$
\Delta u(t)=K_{p} e(t)+K_{i} \int_{0}^{t} e(\tau) d \tau+K_{d} \frac{d e(t)}{d t}
$$

where $e(t)=r_{r e f}(t)-\Delta y_{p}(t)$ and $r_{r e f}$ is the external command (or reference signal). The resulting closed loop characteristic uncertain polynomial for $\left(P_{a, 0}=\frac{P_{s}}{2}, P_{b, 0}=\frac{P_{s}}{2}, \dot{y}_{p, 0}=0, y_{p, 0}=0, u_{0}\right)$ is

computed to be:

$$
\begin{aligned}
& p_{c}\left(s, q, K_{i}, K_{p}, K_{d}\right)= \\
& s^{4}+f_{3}(q) s^{3}+f_{2}\left(q, K_{d}\right) s^{2}+f_{1}\left(q, K_{p}\right) s+f_{0}\left(q, K_{i}\right)
\end{aligned}
$$

where

$$
\begin{aligned}
& f_{3}(q)=\frac{q_{2}}{q_{3}} \\
& f_{2}\left(q, K_{D}\right)=\frac{a A_{p} P_{s}\left(A_{p}+R K_{d} q_{4} T_{b}\right)}{q_{3} q_{1}}, \\
& f_{1}\left(q, K_{p}\right)=\frac{a R A_{p} K_{p} q_{4} P_{s} T_{b}}{q_{3} q_{1}} \\
& f_{0}\left(q, K_{i}\right)=\frac{a R A_{p} K_{i} q_{4} P_{s} T_{b}}{q_{3} q_{1}}
\end{aligned}
$$

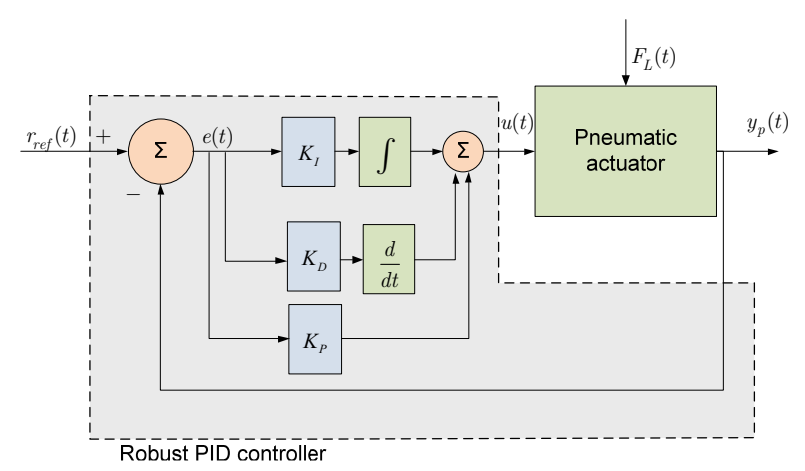

Figure 2. Robust PID control scheme

\subsubsection{Finite step algorithm}

The parameters of the PID controller will be computed using the following algorithm which has been presented in [11]-[13]:

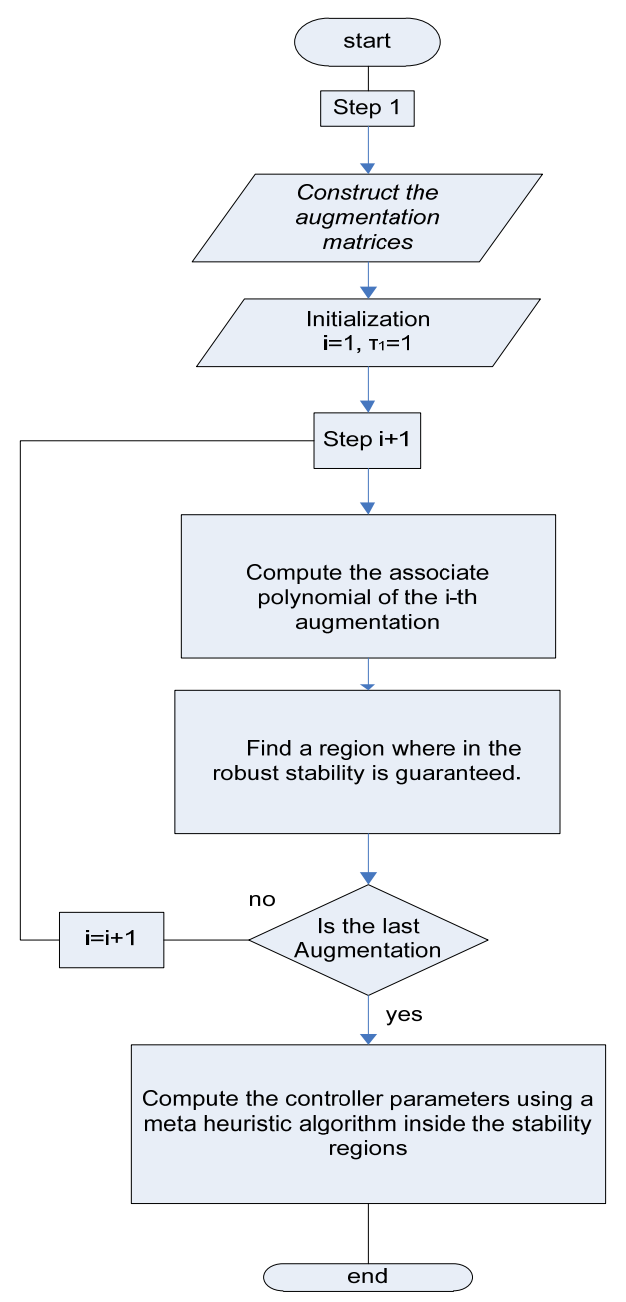

Applying the algorithm to the closed loop characteristic uncertain polynomial (7) the following values are computed

$$
K_{p}=0.3, K_{i}=0.05, K_{d}=0.5
$$

\subsubsection{Simulation results}

Using the data values of Table 1 and 2, the aforementioned PID parameters, the external command of magnitude 0.01 and the external disturbance $0.01 \operatorname{Cos}[3 t]$, closed loop simulation results for the performance of the actuator, for all the range of uncertainties are illustrated in Figures 3 - 7.

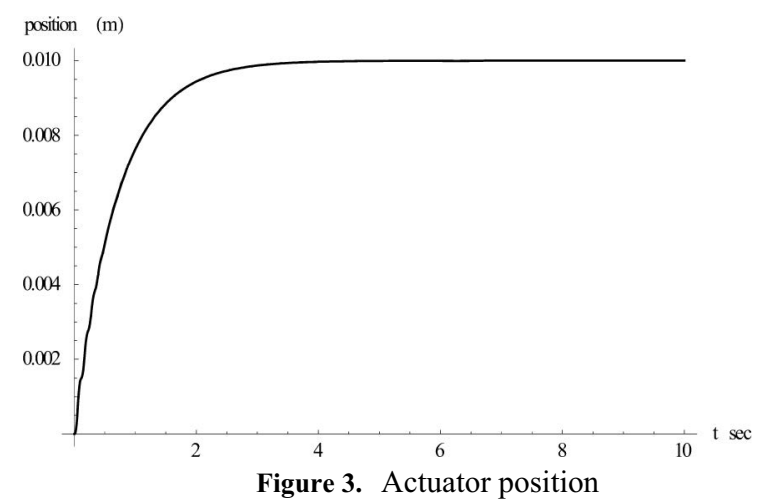



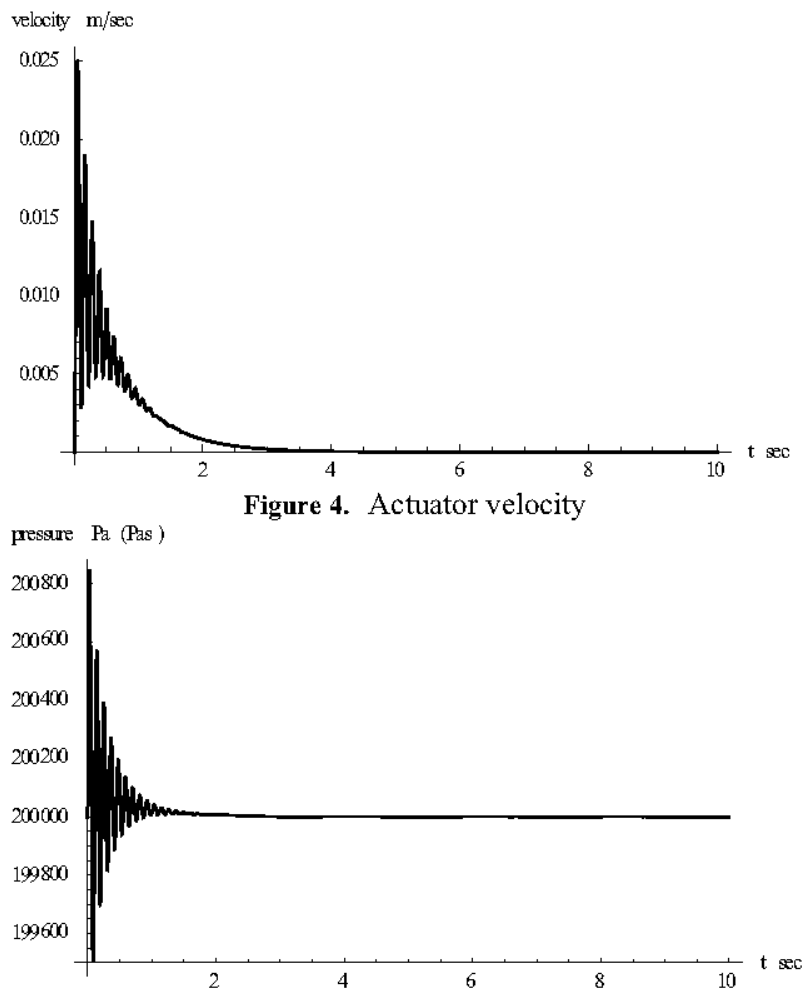

Figure 5. Actuator differential pressure chamber $\mathrm{A}$

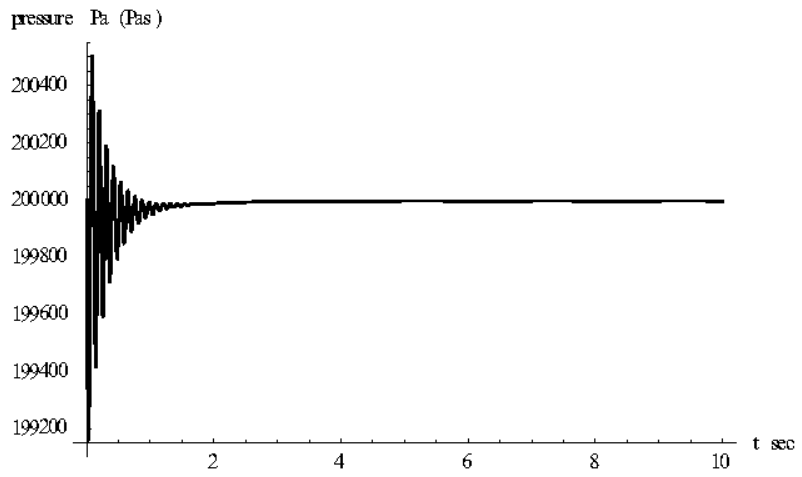

Figure 6. Actuator differential pressure chamber B

\section{Acknowledge}

This research has been co-financed by the European Union (European Social Fund - ESF) and Greek national funds through the Operational Program "Education and Lifelong Learning" of the National Strategic Reference Framework (NSRF) - Research Funding Program: ARCHIMEDES III. Investing in knowledge society through the European Social Fund. (ARCHIMEDES IIISTRENGHTENING RESEARCH GROUPS IN TECHNOLOGICAL EDUCATION, NSRF 2007-2013).

\section{Conclusion}

The problem of controlling the position of a pneumatic actuator has been studied using a robust arbitrary tracking controller. The performance of the controller to external disturbance and uncertainties has been tested to the nonlinear model of the actuator. The present results can easily be applied to real time environment with appropriate sensor and DSP cards.

\section{References}

1 H. E. Merrit (1966). Hydraulic Control Systems, John Wiley and Sons, Inc.,USA.

2 R. L. Woods and Kent L. Lawrence, Modeling and Simulation of Dynamical Systems, Prentice Hall, New Jersey.

3 S. Laghrouche, M. Smaoui, X. Brun and F. Plestan, Robust second order sliding mode controller for electropneumatic actuator, Proceeding of the 2004 American Control Conference Boston, Massachusetts June 30 - July 2, 2004

4 Samsul Bahari Mohd Noor, Hazem I. Ali* and Mohammad Hamiruce Marhaban, Design of combined robust controller for a pneumatic servo actuator system with uncertainty, Scientific Research and Essays Vol. 6(4), pp. 949-965, 18 February, 2011.

5 P. R. Moore, J. Pu, and R. Harrison, Progression of servo pneumatics towards advanced applications, In Fluid Power Circuit, Component and System Design (Edge, K. and Burrows, C., eds). Research Studies Press, 1993, 347-365.

6 R. B. Van Varseveld, and G. M. Bone, Accurate position control of a pneumatic actuator using on/off solenoid valves. IEEE/ASME Trans. Mechatronics, 1997, 2, 195-204.

7 J. Wang, J. Pu, P.R. Moore, and Z. Zhang, Modeling study and servo-control of air motor systems. Int. $J$. Control , 1998, 71, 459-476.

8 J. Wang, J. Pu, and P. R. Moore, A practicable control strategy for servo pneumatic actuator systems. Control Eng. Pract. , 1999, 7 , 1483-1488

9 I.G. French, The robust control of a modern electropneumatic actuator, International Conference on Control, 1988. 88.

10 F. N. Koumboulis, M. G. Skarpetis and M. P. Tzamtzi, "Robust PI Controllers for Command Following with Application to an Electropneumatic Actuator", 14th IEEE Mediterranean Conference on Control and Automation (MED'06), June 28-30, 2006, Università Politecnica delle Marche, Ancona, Italy.

11 M. G. Skarpetis, F. N. Koumboulis, and A. S. Ntellis, Robust Control of Pneumatic Clutch Actuators using Simulated Annealing Techniques, 21st Mediterranean Conference on Control and Automation, June 25-28, 2013, Platanias-Chania, Crete, Greece.

12 M. G. Skarpetis, F. N. Koumboulis and A.S. Ntellis, "Robust Arbitrary Reference Command Tracking with Application to Hydraulic Actuators", 9th Conference on Informatics in Control, Automation and Robotics, Rome Italy, 28-31, July 2012.

$13 \mathrm{~K}$. Wei, and R. Barmish, "Making a polynomial Hurwitz invariant by choice of feedback gain", Int. J. Contr., Vol 50, pp 1025-1038,1989.

14 F.N. Koumboulis, and M.G. Skarpetis, "Robust Triangular Decoupling with Application to 4WS Cars", IEEE Transactions on Automatic Control, vol. 45 , pp. $344-352,2000$. 